\title{
THE ROLE OF VERBAL ACTIVITIES IN THE CONDITIONING OF HUMAN SUBJECTS
}

\author{
BY HULSEY CASON \\ Unioersity of Wisconsin
}

After summarizing the experimental literature on conditioned withdrawal responses with shock as the conditioning stimulus in adult human subjects (8), Dr. G. H. S. Razran states that "while the withdrawal response to an electric shock is undoubtedly most useful in animal conditioning and of great interest in some special problems of human conditioning, its general value as a method for the discovery of the laws of conditioning in adult human beings is extremely limited." Dr. Razran's reviews of the experimental literature on the conditioned response $(5,6,7,8)$ show a degree of care and patience that is unusual, and they should be studied carefully by all who are interested in this subject. But after reading Dr. Razran's review of conditioned hand withdrawal responses in human subjects (8) and his review of conditioned responses in children (6), especially those parts of the latter which are concerned with conditioning the motor responses of older children, I have become more than ever convinced that the well known verbal activities, although more frequently neglected than not in the strictly behavioristic studies of the conditioned response, are somewhat central and basic in most of the conditioning of motor responses in human subjects. The present view of the role of verbal activities in the conditioning of human subjects has been influenced by the experience of carrying out an earlier experimental study in which an attempt was made to condition hand withdrawal responses in human subjects (2), and by the experimental investigations of Hamel (3) and Schilder (9).

In some of the conditioned hand withdrawal experiments, the movements of the hand in one direction have been ac- 
curately registered by means of instruments, and several investigators have not felt badly about neglecting the implicit verbal activities of their subjects because these activities cannot be registered with the same degree of accuracy. The suggestion has even been made that any information about the subject's conscious thought processes is worse than no information at all. One may fairly express the sentiments of one group of experimenters in the following words: "Let us leave the conscious thought processes to the mentalists and the internal functions of the body to the physiologists and seek the general principles of externally observable behavior. And, furthermore, let us assume that the people who act as subjects for us are animals, or at least let us treat them as if they were animals."

It does not seem reasonable, however, to neglect the thinking and inner speech of human subjects just because the symbolic activities of subhuman animals are difficult to observe. ${ }^{1}$ It is only on special occasions that human subjects have been treated as if they were subhuman animals, and the kind of subhuman animal selected for the occasion has not always been specified. The question might also be raised: if one is under obligation to treat people as if they were subhuman animals, why not treat all of the different subhuman animals alike? Should monkeys and rats be treated as if they were fishes and birds? Where should the line be drawn, or should any line be drawn? If the thought processes of people should be neglected because they are not found in rats, should we not also neglect those organic processes of monkeys which are not found in rats? It seems reasonable to believe that none of these organic processes should be neglected.

It appears that the suggestion of Bechterev (I) and Watson (II), that the conditioned hand withdrawal movement can take the place of the verbal report method in studying sensory discrimination in human subjects, is generally regarded as a mistake. It is even more generally recognized that one can pay proper attention to the role of verbal activities in motor

1 Thinking in human subjects may include some organic processes that are not strictly verbal in nature (Watson, 12, pp. 202-215). 
learning and still be a strict behaviorist (Watson, 12, pp. $180-215)$, although this attitude is not always taken in practise. The limitations of the verbal report method have been pointed out with considerable enthusiasm by some writers, but there are many organic activities which are by no means as accessible as inner speech. Verbal activities are generally conscious, but under ordinary circumstances one is also aware of what the hand is doing when a new act involving the hand is being learned. One is not conscious of all of the physiological processes that take place in any movement of the body. Movements of the hand may be involuntary, but inner speech and/or thinking are not entirely voluntary. Movements of the hand may acquire some of the characteristics of reflexes, as in reaction time experiments, but vocal and subvocal speech, in some people at least, is relatively automatic.

Several students of the conditioned response have had an aversion for the verbal report method or introspection because it seemed in one way or another to be related to 'consciousness,' but if such concepts as this one are laid aside there should be no objection to taking account of several organic processes that are present while learning takes place. Although it is not possible to study all of the simultaneous organic processes at once, it is not difficult to study more than one organic activity at a time. The usual custom is to attach the recording instruments to some convenient part of the body which is crucial and significant in the process being studied, so that the observations and results will have the maximum scientific value. I am inclined to think that when conditioned hand withdrawal movements of intelligent human subjects are being studied, it is a mistake to pay no attention at all to their implicit verbal activities.

When people have been treated as if they were animals and when no verbal reports have been asked for or permitted, the conditioned hand withdrawal responses with shock as the conditioning stimulus have on several occasions shown the most peculiar characteristics. A fairly large per cent of supposedly intelligent human subjects have not been able to learn to withdraw their hand when they heard a sound; and some 
of these subjects have, for one reason or another, been excused from further efforts. Some of the more persistent experimenters were not able to teach their human subjects to move their hand when they heard a sound after more than one thousand repetitions of the training stimuli. Other experimenters, however, without seeming to put forth any unusual effort, have been able to teach their subjects to withdraw their hand when they heard a sound after only one repetition of the training stimuli. Several subjects have established this connection in themselves somewhat independently of the formal training. Conditioned hand withdrawal responses have been established in the hypnotic state more easily than in the waking state; normal and subnormal adults have shown only a slight difference in the efficiency of learning this response; and some of the subhuman animals have learned a withdrawal response more efficiently than human subjects. In Osipova's study of school children, with the sound of an electric bell as the conditioned stimulus and an electric shock as the conditioning stimulus (Razran, 6, pp. 60-64), the learning was more efficient in children under 14 than in older children, and it was more efficient in subnormal children than in normal children of the same age. ${ }^{2}$ These results are somewhat surprising, and they cannot be readily explained by reference to the nervous connections with the hand alone. They suggest that there was some factor in the organism which the experimenters did not consider. ${ }^{3}$

The conditioned hand withdrawal responses which have been obtained do not have the speed and regularity of the withdrawal movements of the hand which are generally present in the simple reaction time experiment. The reason for this difference is apparently found in the fact that in the reaction time experiment, but not in the conditioned hand withdrawal experiment, the subject is told what he is supposed to do; and in some of the conditioned hand withdrawal experiments the subject may not know that he is supposed to do

2 Workers in Bechterev's laboratory have used words or commands as conditioned stimuli with school children as subjects (Razran, 6, pp. 60, 7x-73).

The explanations of these irregularities given by Bechterev ( $x, p .356)$ and Razran $(8$, p. 140$)$ are not entirely clear. 
anything. When several hundred or a few thousand trials are made in the reaction time experiment, the hand withdrawal movement tends to acquire several of the characteristics of involuntary automatic acts. The well practised movement of the hand and arm in the reaction time experiment bears a close resemblance to a fairly large number of learned movements which appear to be quite reflex in nature, such as the individual acts involved in operating an automobile, and the individual movements involved in the well practised habits of sitting, standing, walking, dancing, chewing, swimming, typewriting, playing musical instruments, holding and carrying objects in the hand and under the arm, moving the hand towards one's hat when it is about to be blown off by the wind, jumping when a flash of lightning is seen, compensatory movements in falling, and moving the eyes along the lines of a printed page. Although many skilled acts become automatic, involuntary, and reflex in nature, the conditioned hand withdrawal movements acquire these characteristics only occasionally. Practically all of the responses of striped muscles which people learn can be learned more efficiently, and retained in a much more predictable manner, when the person is given the usual verbal information in regard to the act which he is to learn.

If the verbal activities of people were not closely connected with the conditioning of their motor responses, these comments on the importance of speech in conditioning would not be so pertinent, but the causal connection between verbal activities and the conditioning of motor responses is quite close. The desirability and in some cases the necessity of keeping the verbal processes in mind in connection with certain types of motor learning may be made more plausible by the three following examples.

I. If it is desired to form connections between several verbal stimuli and several movements of the right hand, the experimenter might say to the subject: "In your right hand, let the number of the little finger be one, the ring finger two, the middle finger three, the forefinger four, and the thumb five. Now when I speak a number from one to five, will 
you tap on the table with the corresponding thumb or finger, but do not begin tapping until I finish speaking all of the numbers?" If the experimenter then says "12345432123454321," or some other similar and easily remembered series, the subject can tap out the appropriate combination on the table. In this illustration, the different verbal stimuli are given quite close together in time.

2. If the experimenter wishes to establish a connection between a present stimulus and a response which occurred ten days in the past, and which we shall assume has not occurred during the past ten days, the experimenter's instructions to the subject could take the following form. "When I speak the word 'dance,' will you execute the dance step which you showed me about ten days ago." If $E$ then speaks the word 'dance,' $S$ can execute the step. Or $E$ could say, "When I say 'Beethoven,' will you play on the piano the musical composition which you played for us about ten days ago." If $E$ then speaks the composer's name, $S$ can play the selection on the piano.

In the two illustrations just given, the responses occurred ten days in the past, and the stimulus is given in the present; but it does not seem desirable to regard this very common type of learning as backward conditioning or as backward association, because the stimuli and responses overlap each other. The stimuli and the responses are concurrent in (a) learning, (b) retention, and (c) reproduction, for one does not have stimuli without responses or responses without stimuli. If the stimuli and the responses with which the stimuli are connected were not concurrent events, the one could not possibly have any causal influence on the other.

3. If $E$ would like to form connections in $S$ between present stimuli and future responses, he could give $S$ the following instructions. "At $11: 26$ A.M. Friday week, begin writing poem $X$ (which you already know) on the typewriter, and continue writing this poem for four minutes." $S$ can use his own method of giving himself the necessary stimuli on the later occasion.

In this illustration, the verbal stimuli are given in the 
present, and the motor responses occur in the future; but it does not seem desirable to regard this very common form of learning as a trace or successive conditioned response, partly because the responses in question would not occur in the future if some kind of stimuli were not present when or just before the responses occurred.

I think the reader will recognize that these three forms of learning, retention, and reproduction are frequently and widely used, and it would seem that our most general principles or laws of learning should, in some measure at least, take these forms of learning into account. Each of the three forms of learning described above has the following general characteristics:

1. Verbal activities are fundamental and basic in each of the three forms of learning, and by verbal activities we do not mean activities of the central nervous system alone.

2. No subhuman animal can be taught to do anything as complicated as the three acts described above in the same period of time, and no subhuman animal can be taught some of these acts in any period of time.

3. Intelligent human subjects can acquire the connections in each of the three forms of learning described above after only one repetition of the combined stimuli.

4. Since the formation of the connections requires in each of the three cases only one repetition of the combined stimuli, the alleged laws of 'use' and 'frequency' do not afford a plausible description of the learning process.

5. Since the acts learned in each of the three forms of learning described above may be pleasant, unpleasant, or indifferent, the pleasure-pain theory of learning does not afford an adequate description of the learning process.

6 . The retention and reproduction of the acts or connections in each of the three kinds of learning described above are highly efficient and quite specific.

7. Finally, the fact that verbal activities are involved in each of the three forms of learning, retention, and reproduction described above seems on the whole to be more significant and basic than the existence of Gestalt patterns on some occasions. 
Each of the three forms of learning described above is also on a higher and more complicated organic level than the simple type of the conditioned response.

When an intelligent person is told what he is to learn, he can readily form efficient associations between many different kinds of stimuli affecting his eye, or his ear, and the complicated responses of writing the answer with a pencil or pen, in some cases writing the answer on a typewriter, possibly writing the answer in any one of three or four foreign languages, or speaking the answer, thinking about it, recognizing it, etc. In cases of this kind the learning does not occur in the eye, in the ear, or in the hand, but largely in the sensoryneuro-motor verbal activities. Perhaps one should say that the learning occurs principally in the central nervous verbal activities, but the sensory and motor verbal activities are also necessary. These organic verbal activities of people are also central and basic in redintegrative learning, in serial learning, in the learning of the affectivities, in the learning of practically all kinds of skilled motor performances which involve the striped muscles, and also in the kind of learning situations which Professor Thorndike has used in most of his recent experiments (10). People learn better when they know they are supposed to learn something and when they know what it is they are supposed to learn.

In the present paper I have not claimed that verbal learning is the only kind of learning, and I have not assumed that the general principles or laws of learning, retention, and reproduction can be established best by a study of verbal learning, or even by a study of the learning processes of human subjects. Our principal suggestions are that some organic processes are more important than others in the learning processes of people, and that the analytical method of science requires that there should be a proper consideration of verbal activities in human motor learning. Verbal activities should be considered in spite of, or perhaps partly because of, the fact that they are conscious. Hudgins' experiment (4) in which the pupillary response of human subjects was conditioned to verbal stimuli is suggestive in this connection. 
The human subjects in some of the conditioned hand withdrawal experiments have been carefully isolated from the experimenter; and they have been left alone with their thoughts. The excellent stimulating and recording apparatus which has sometimes been used has not overcome or eliminated the causal influence of the verbal activities. In studying conditioned hand withdrawal responses it does not seem a defensible scientific method to limit one's self to a behavioristic description of the hand itself when the psychological processes which afford a fairly satisfactory explanation of what the hand does are located elsewhere in the body.

\section{REFERENCES}

I. Becrterev, V. M., General principles of human reflexology (tr. from the 4th 1928 Russian edition), 1932. Bechterev gives many references to his carlier work in this curious book.

2. Cason, Hulsex, An attempt to condition hand withdrawal responses in human subjects, to be published in $J$. Exper. Psychol.

3. Hamex, I. A., A study and analysis of the conditioned reflex, Psychol. Monog., 1919, 27, No. 118.

4. Hudarss, C. V., Conditioning and the voluntary control of the pupillary light reflex, J. Gen. Psychol., 1933, 8, 3-51.

5. Razran, G. H. S., and Warden, C. J., The sensory capacities of the dog as studied by the conditioned reflex method (Russian schools), Psychol. Bull., 1929, 26, 202-222.

6. RAzRAN, G. H. S., Conditioned responses in children: a behavioral and quantitative critical review of experimental studies, Arch. of Psychol., 1933, No. 148.

7. Razran, G. H. S., Conditioned responses in animals other than dogs, Psychol. Bull., $1933,30,261-324$.

8. RAzRAN, G. H. S., Conditioned withdrawal responses with shock as the conditioning stimulus in adult human subjects, Psychol. Bull., 1934, 31, 111-143.

9. Scrilder, Paul., Conditioned reflezes, Arch. Neurol. Ef Psychiar., 1929, 22, 425443.

10. ThorndiKe, E. L., and otaers, The fundamentals of learning, 1932.

11. Watson, J. B., The place of the conditioned reflex in psychology, Psychor. Rev., $1916,23,89-116$.

12. Watson, J. B., Behaviorism, 1925.

[MS. received April 26, 1934] 